\title{
Analysis and management of avariation to a fluvial transport vessel caused by collision
}

\author{
C Babiş ${ }^{1}$, O R Chivu ${ }^{1}$, A Dimitrescu ${ }^{2}$, L Dascalu ${ }^{1}$, E Niculae $^{2}$, G Iacobescu ${ }^{1}$, A \\ Semenescu $^{3}$, O D Negoita ${ }^{4}$ and A Purcarea \\ ${ }^{1}$ Welding and Material Technology Department, Politehnica University of Bucharest, Romania \\ ${ }^{2}$ Theory of Mechanisms and Robots Department, Politehnica University of Bucharest, \\ Romania \\ ${ }^{3}$ Economics Engineering Department, Politehnica University of Bucharest, Romania \\ ${ }^{4}$ Faculty of Entrepreneurship, Business Engineering and Management, Politehnica University \\ of Bucharest, Romania \\ claudiubbs@gmail.com
}

\begin{abstract}
In general, the body of the ship is a welded metal structure made up of the shell and bone. The paper aims is to analyze and present the solution for the collision damage to a river transport vessel. The problem is treated as in the case of a typical failure of welded constructions. In this regard, the fault will be described, after which the stages of the fault remedy will be presented.
\end{abstract}

Keywords: colision, failure, damage,crash.

\section{Introduction}

Approach (synonymous with collision) is the unexpected crash of two ships or the crash of a ship by an obstacle. The approach may take place between two ships, whether sea or river, irrespective of the nature of the water in which it took place.

If a ship hits a fixed body (quay, estacade, pontoon, bridge, lock, etc.), a sinking object (wreck, anchor, rock, etc.) or a floating body that does not have the quality of a vessel floating crane, drifting craft, hull of a ship under construction), the collision is not considered as an approach, and the determination of liability is determined by common law.

According to the Brussels Convention of 23 September. 1910 on the approach, the damage to a ship or its cargo, as well as the injury of the people on board caused by the propeller current or by the sucking effect produced by another ship which has passed too close to the first, is considered as a damage produced by approach, even if it was not a direct hit.

From a legal point of view, the approach can be "maritime" when the crash occurs between two seagoing ships or between a naval and an inland waterway, and "fluvial" when the crash occurred in the inland waters between two river ships. The "International Convention of Geneva of 9 December 1930", which regulates the civil consequences of approaching ships of different nationalities, also applies to river approaches the rules of the sea approach.

The determination of liability in the case of an approach between sea-going vessels or between a sea-going vessel and one of inland navigation, irrespective of the waters in which it occurred, shall in principle be established as follows:

- If the case was due to a case of force majeure or there are doubts about the cause that caused it, each ship suffered its damage, even if at the time of the accident or both, they were 
anchored. The damages that occurred to the ships or their cargoes are considered "private damages";

- If the guilty approach is one of the ships in collision, this ship is liable for the damage caused;

- When both ships are guilty, civil liability shall be determined in proportion to the gravity of the fault of each of them, without any solidarity towards third parties;

- The third-party approach is the case where a third vessel has pushed the approaching vessel over the approaching ship or has imposed on the latter an avoidance maneuver that has caused the approach. For the approaching vessel, the deed of the third vessel is a case of force majeure provided that its action has been unpredictable and inevitable. In this case, the ship being approached must claim compensation from the third vessel and the approaching vessel may be in a situation of joint failure;

- Accident ship liability remains subservient even when the approach is caused by the pilot's fault.

The shipping vessel that has suffered collision damage is shown in Figure 1.

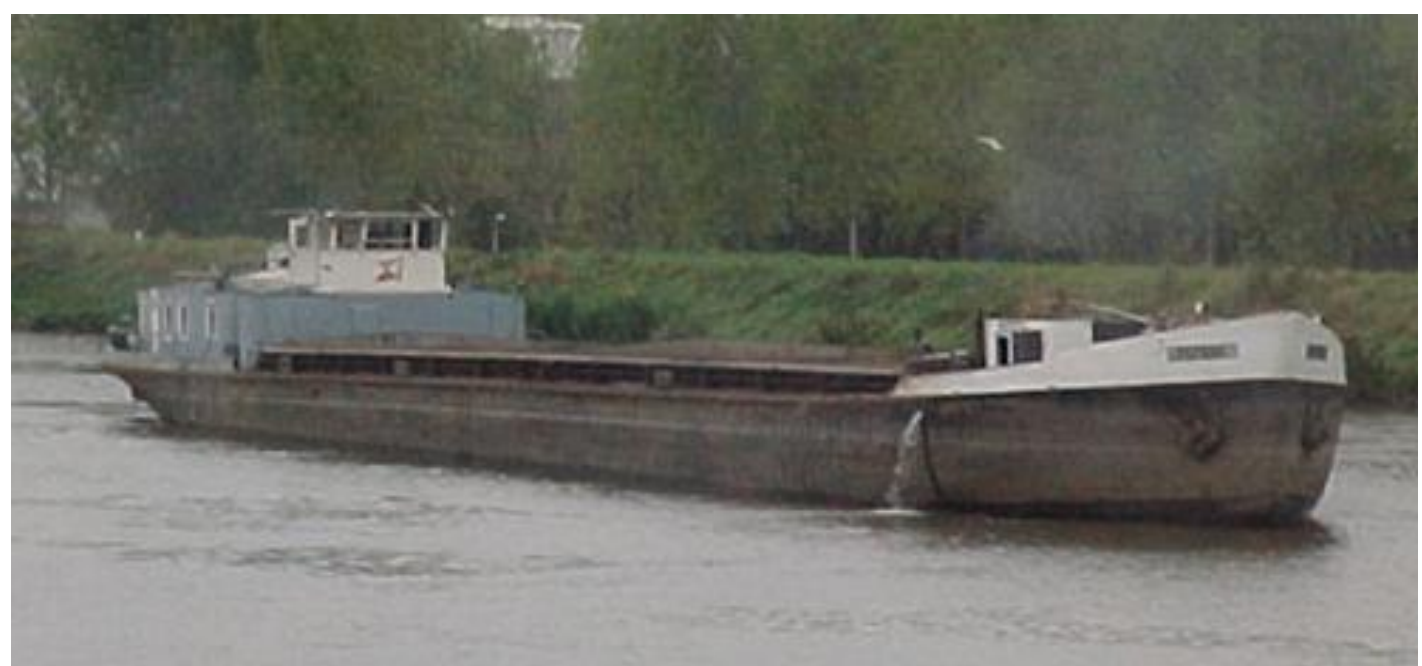

Figure 1. River transport vessel

The welded structure damaged by the colision is part of the metal body of a river ship to transport bulk goods [1],[2],[3],[4],[5],[6],[7],[8],[9],[10],[11].

The body of the vessel consists of the shell of the vessel, which is made of 8 to $12 \mathrm{~mm}$ thick sheets, the material used being the naval A-type sheet with the yield limit up to $235 \mathrm{~N} / \mathrm{mm} 2$ and the ship's bracing consisting of transverse and longitudinal elements which are divided into two categories:

- strengthened elements - composite T-shaped profiles, made of heart and platen, welded together; are made of sheet thickness between $8-10 \mathrm{~mm}$ of the naval sheet type A.

- simple elements - HP120x8 bulb profiles, material S235, category A.

\section{Experimental research}

Experimental research was carried out for the purpose of analyzing the ship's body failure, a collision damage. Photographs, dimensional measurements, chemical composition of damaged sheet material, hardness and resilience tests were determined.

The damage consists of the visible plastic deformations with the naked eye of both the sheathing, the shell and the blade in the area of the shell and the bottom of the ship, as shown in Figure 2 and Figure 3. As a result of the research, it has been found that the two categories of deformations, both of the sheathing and of the ship's blade, in that area, lead to the weakening of the ship's longitudinal resistance, which can have disastrous effects in the future operation of the ship. 
The weakening of the longitudinal resistance, by deformation of the blade, affects the body of the ship, considered a beam on the elastic medium (water). This weakening of the longitudinal resistance can cause the body to break in two loading and transport conditions.

Also, due to the researches carried out, there was also a loss of local resistance, by damaging the welding seams between the sheets of the shell, which leads to the non-sealing of the body's ship, without ensuring the conditions of immovability.

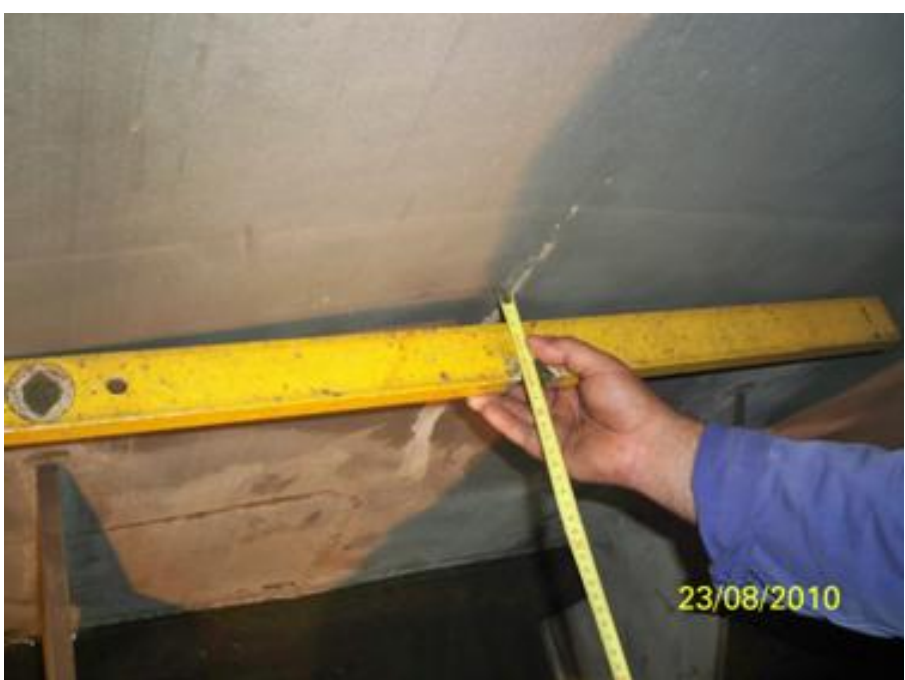

Figure 2. Movement of the bed sheets by $30 \mathrm{~mm}$ over a length of $1 \mathrm{~m}$

The deformation of the blade in the area of the shell and the bottom of the vessel can be seen in Figure 3.

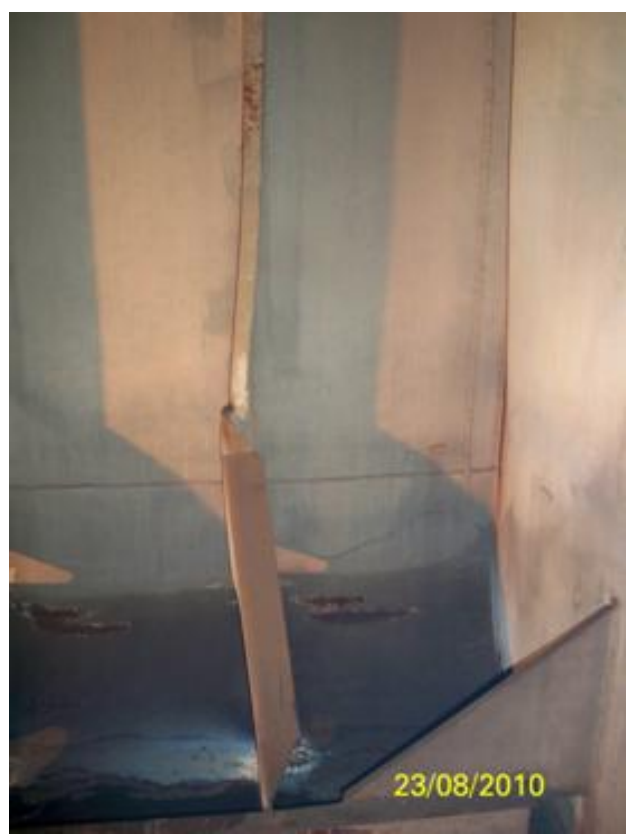

Figure 3. Deformation of the blade in the shell and bottom of the ship

\section{Experimental results}

The experimental results consist in the results obtained after the application of the remedies for the damage. 
The damage described above is incompatible with the safe operation of the ship, both in terms of crew safety and in terms of the safety of the cargo carried. In order to remedy the damage, it is necessary to decommission the ship and enter a shipyard, to dock and repair the damaged area.

The repair will consist of changing the boards and the body of the ship, with at least one additional intercostal distance along the ship's length, to the bow and aft, to the damaged area according to the classification register rules. The Classification Registry is the body which finds at the end of the repair whether the ship is again capable of navigating both from the point of view of crew safety and compliance with the rules of navigation on the river and from the point of view of the safety of the cargo during transport.

In order to remedy the damage, it is necessary to carry out cutting and straightening of damaged parts, assembly and assembly of damaged parts and welding and control operations.

Of the components cutting and straightening operations, we mention:

- Cutting and removing the sides of the panel over a length of approx. $2 \mathrm{~m}$ means four intercostal distances. The board is replaced with a thickness of $8 \mathrm{~mm}$ and is $1.5 \mathrm{~m}$ high.

- Taking and removing the gourmet plates over a length of approx. $2 \mathrm{~m}$, means 4 intercostal distance. The table of the gourd, replaced, is thick. $12 \mathrm{~mm}$ and has a width of $1 \mathrm{~m}$.

- Transition and removal of the transverse blade in the area of the shell, on 4 ribs. The blade in the area is made up of the HP $120 \times 8$ profile. Replace the profile at a height of $1.75 \mathrm{~m}$.

- Ting and removing a portion of the reinforced blade from the bottom and the gourd: for four varges the heart is cut, the thick sheet. 8, on an area. of $1250 \times 600 \mathrm{~mm}$ and cut out the 120x 10 payload on a $1400 \mathrm{~mm}$ vario length, as shown in Figure 4.

- The removal and removal of a watertight cross-section of the wall, which has suffered deformations, the dimensions being $2150 \mathrm{~mm}$, height and $600 \mathrm{~mm}$ width, the sheet having 8 $\mathrm{mm}$ thickness, as shown in Figure 5.

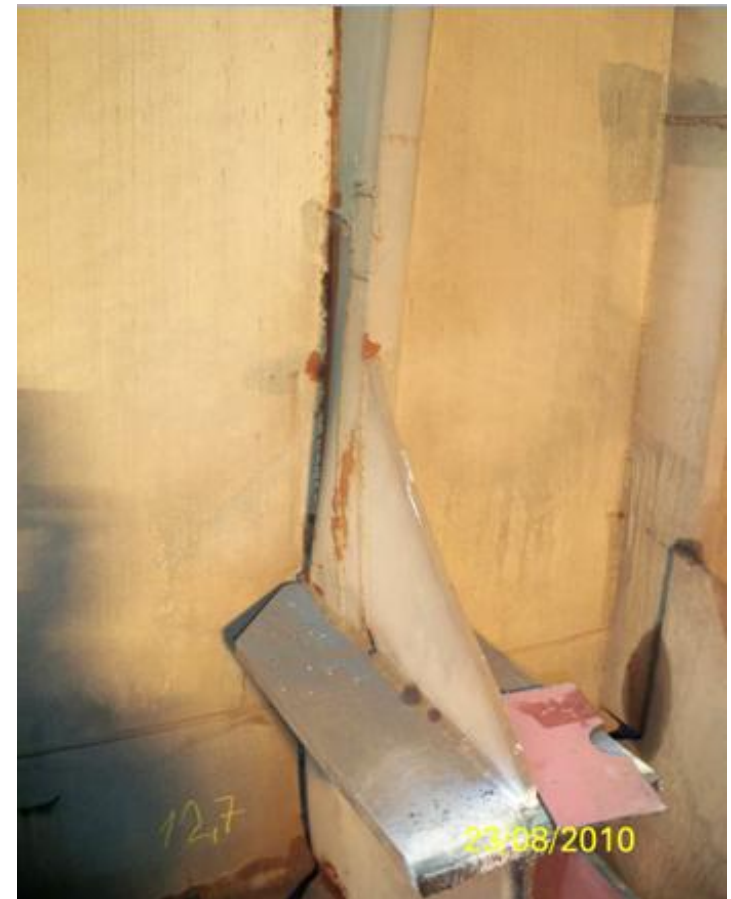

Figure 4. Cutting and removing the portions damaged in a varanga - heart and payment

The damaged area of the sheat metal of the transverse wall can be seen in Figure 5. 


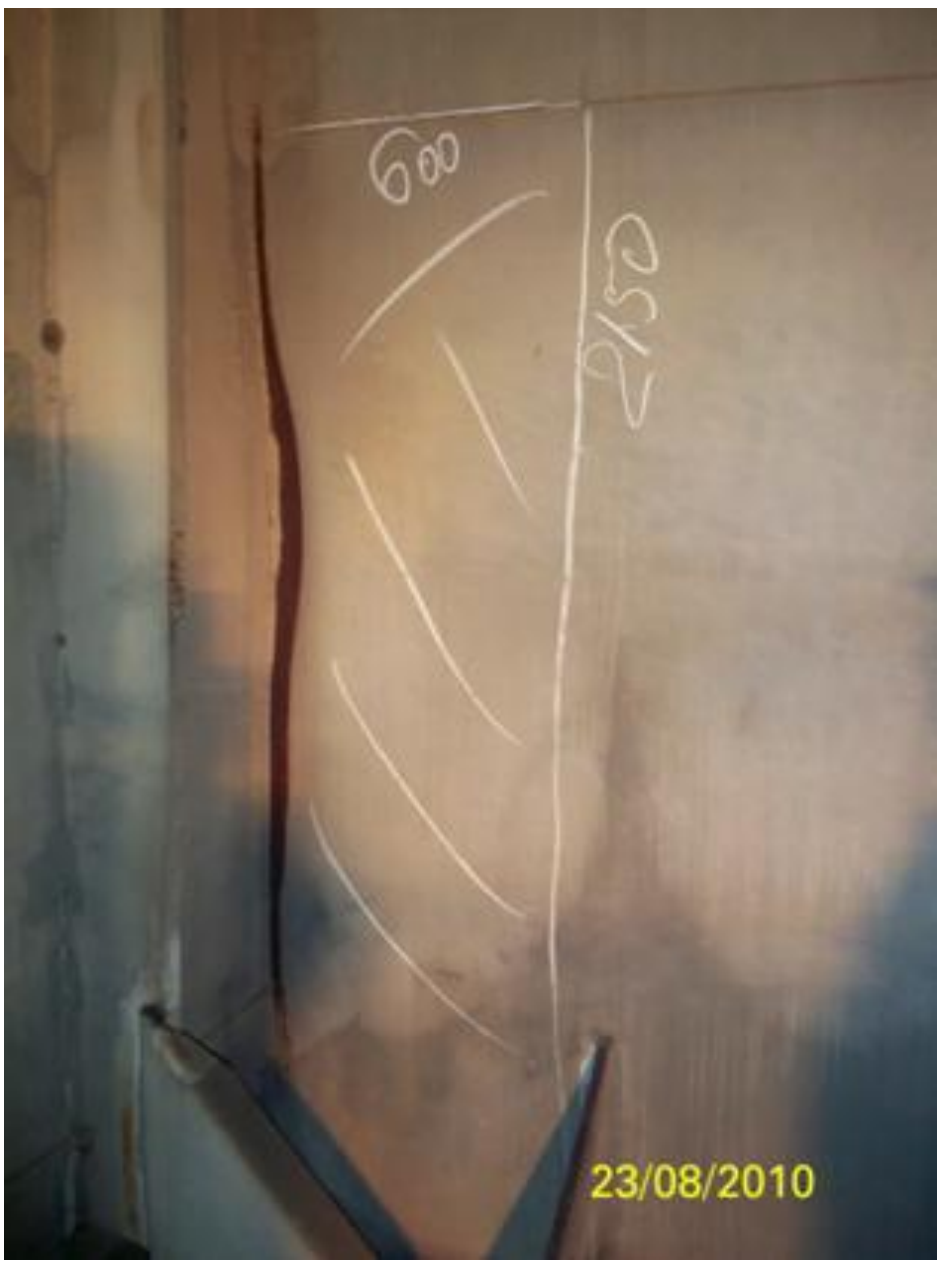

Figure 5. Damaged area of the transverse wall board

The manufacturing and assembly of damaged parts consisted of:

- Configuring and mounting in the side of a board a size 2000 x 1500 × $8 \mathrm{~mm}-192 \mathrm{~kg}$.

- Making and fitting a table of dimensions in the mouth and bottom area 2000 x 1000 x $12 \mathrm{~mm}$ $288 \mathrm{~kg}$

- Configuring and mounting the transversal blade in the shell area, on 4 ribs. The blade in the area is made up of the HP120x8 profile. It produces and mounts 4 HP 120x 8 profiles of length $1.75 \mathrm{~m}-56 \mathrm{~kg}$

- Confection of 4 pieces of 1250 x 600 xdf $8 \mathrm{~mm}$ sheet and 4 pieces of $1400 \times 120 \times 10 \mathrm{~mm}$ sheet and fitting them as insertion in 4 vargeages in the damaged area $-246 \mathrm{~kg}$

- Making a $2150 \times 600 \times 8 \mathrm{~mm}$ table and fitting it into the transverse wall, in the damage area $83 \mathrm{~kg}$.

Figure 6 shows an insertion of blackboard in the heart.

Among the welding and control operations are:

- Surveying, with total entry of mounted parts.

- Conducting fluid tightness samples, welding cords from the joints of the sheets, from the repaired area.

- Performing GAMA non-destructive control samples to check the total penetration of the welding cords and the continuity of the welding cords between the welded boss members and the bumper frame. 
Damage repair operations should be done with care, as many other damage may occur due to improperly operated operations.

Many damages arise from imperfections in material. Both internal imperfections and surface imperfections can reduce the overall resistance of the material, creating preferential paths for crack propagation, acting as notches, serve as places for preferential piting, or create paths for intergranular corrosion. Examples of segregation, lamination, inclusions, porosity, gaps and other imperfections can be exemplified here.

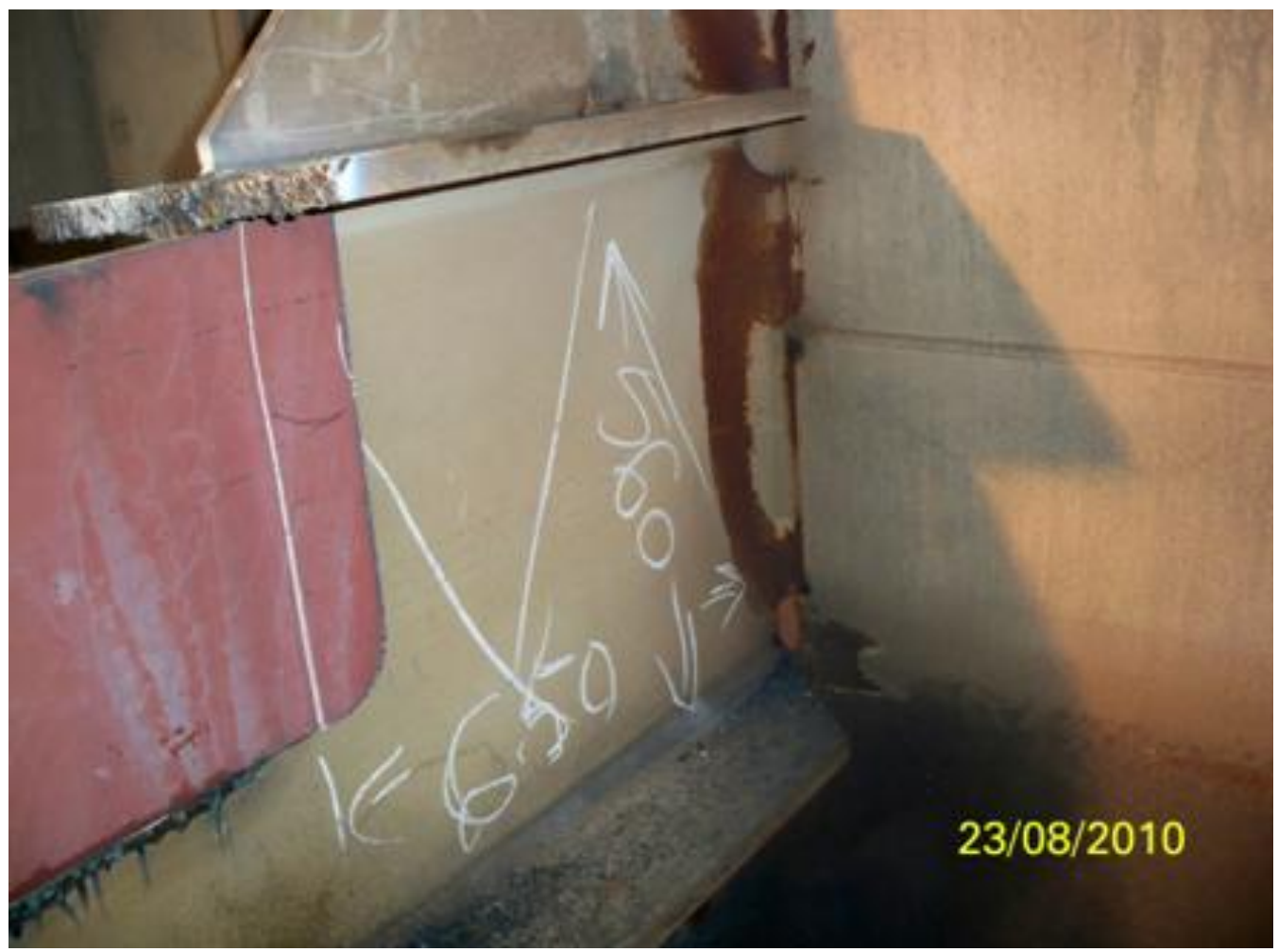

Figure 6. Sheet insertion in the heart - the heart plate

Cold welds, inclusions, porosity, gaps and retards may present special problems in molds. For example, an aluminum alloy pump fitting that contained a steel insert has yielded fracture due to a preexisting imperfection. The discontinuity of the microstructure on the two parts of the crack in this cast piece, the glossy appearance of the conjugate breaking surfaces, the presence of the gas porosities and the absence of any other abnormality in the cast metal identified the imperfection in which the rupture was initiated as a cold welding that occurred in during the casting operation.

Overlaps, stratification, retrieval, cavities and fiber are frequently linked to forged damage. Susceptibility to damage is sometimes linked to inappropriate, incomplete or ambiguous processing specifications, changes made without complete evaluation and operator errors or accidental degradation.

Cold deformation and related operations such as deep drawing, stretching, extension, reduction and bending produce high residual stresses. These operations sometimes alter local or thick mechanical features, produce microcracks or macrocracks and lead to local exhaustion of ductility. Surface effects and metallurgical changes caused by machining have an influence on fatigue strength, fracture toughness and corrosion resistance. Anisotropy of characteristics, areas of dissimilar material and change of orientation of residual stresses can also be introduced, leading to harmful effects, to the susceptibility to service failure of the finished product. 
Shearing, blackening and punching induce residual stresses. The rough or uneven edges are tension concentrators.

Chopping and grinding often removes residual stresses and roughness that stresses tension. Thermal cutting and roughing can initiate fatigue cracking in a forged steel crankshaft. Severe rectification is a source of overheating and subsequent local soaking. It is known that severe abrasion usually produces capillary cracking in the curable steels.

Marking of shock or electrochemical attack is a potential source of damage if done in a highly tense region of the piece. Electric sparking produces melting and a ZIT (an area of the heat affected zone). They probably cause cracking in the service if the correct piece is not controlled, especially in tensile areas of hardened steel over 50-55 HRC.

Inappropriate heat treatment produces in a variety of forms such as overheating, sublimation, use of unacceptably low tempering temperature, the introduction of excessive thermal gradients, and the use of misting, recovery, annealing and aging conditions inappropriate for a specific alloy or piece. Decarburization during heat treatment sometimes induces fatigue damage due to the strong reduction of the fatigue limit of the surface and damage by distortion on small portions that reduce the average cross section resistance. Decarbonation in particular is detrimental to the service life of springs and small trees where surface tensions are usually very high.

Acid pickling and galvanizing (especially at low cathodic yield) are well known for their ability to produce hydrogen loading and therefore hydrogen degradation of high strength steels.

Chemical and electrochemical cleaning and chemical attack in which hydrogen is generated produce similar effects, especially when these processes are immediately followed by the deposition of metallic coatings that prevents the absorption of hydrogen from the base metal. Work procedures must be carefully developed in such applications to minimize hydrogen uptake by subsequent appropriate heating procedures.

Welding can lead to damage by a variety of mechanisms unless proper precautions are taken. One of the most serious welding-related failures is the corrosion cracking of austenitic stainless steels, especially welded to boilers, heat exchangers and vessels under pressure. In some cases, the welding operation, which itself introduces a very high thermal flux, can transmit the susceptibility of the metal to corrosion cracking under stress.

In other situations, strain relief after welding may be the sensitizing factor leading to failure. When welding is done under severe constraining conditions (eg large parts or improper fasteners), welding metal shrinkage and ZIT during cooling cause residual tensions that can suddenly cause cracking or cracking in service.

ISelecting an inappropriate metal or using excessive heat during welding can cause similar effects. If careful and closely-developed procedures have not been developed, welding reconditioning of worn or low-end parts such as large shafts (especially high-strength steel) is likely to suddenly cause cracking or reduced fatigue strength. Reconditioning a piece that was rejected during a manufacturing stage takes the piece out of the normal production channels and can thus introduce more likely manufacturing errors.

\section{Conclusions}

In total, we produce and mount parts with a mass of $900 \mathrm{~kg}$.

The total mass of the pieces to be assembled, the total mass of the damaged potions removed from the ship's body, and the complexity of the works done to repair the damage, are the basis for drawing up the worksheet, which in turn is the basis for drawing up the contract between the shipyard and the owner of the ship and the pricing of the damage remedy.

Welding can lead to damage by a variety of mechanisms unless proper precautions are taken. One of the most serious welding-related failures is the corrosion cracking of austenitic stainless steels, especially welded to boilers, heat exchangers and vessels under pressure. In some cases, the welding operation, which itself introduces a very high thermal flux, can transmit the susceptibility of the metal to corrosion cracking under stress. 
Damage repair operations should be done with care, as many other damage may occur due to improperly operated operations.

Many damages arise from imperfections in material. Both internal imperfections and surface imperfections can reduce the overall resistance of the material, creating preferential paths for crack propagation, acting as notches, serve as places for preferential piting, or create paths for intergranular corrosion. Examples of segregation, lamination, inclusions, porosity, gaps and other imperfections can be exemplified here.

\section{References}

[1] Monika O., Peter P.,Milan U.,Fracture mechanism differences created by fatigue and impact test, Materialstoday Proceedings, vol. 4/issue 3, pp 5921-5924, 2017

[2] Zhao-Ling W, Heng X Direct modeling of multi-axial fatigue failure for metals, International Journal of Solids and Structures, pp 216-231, 2017

[3] Pavel, A., Siguranţa în funcţionare a utilajelor petrochimice, Editura Tehnică, vol 3, pp 5-365, 1988

[4] Armando L., Rama I., José A., Carlos A., Branco G., Fatigue behaviour of $T$ welded joints rehabilitated by tungsten inert gas and plasma dressig, Materials and Design, vol 32, pp 47054713, 2011

[5] Barsom, J.M., Rolfe, S.T., Fracture and Fatigue Control, Edition 2, Prentice Hall, 1987.

[6] Bathias, C., Paris, P.C., Gigacyclic Fatigue in Mechanical Practice, Marcel Decker, New York, 2005.

[7] Rusu, O., Teodorescu, M., Laşcu-Simion, N., Oboseala metalelor, vol.1, Editura tehnică, Bucureşti, 1992.

[8] ***, Fatigue Design Handbook, Second Edition, SAE, Warrendale, 1988.

[9] Bejan, M., În lumea unităţilor de măsură. Ediţia a doua revăzută şi adăugită. Editura Academiei Române şi Editura AGIR, Bucureşti, 2005.

[10] Armando L., Rama I., José A., Carlos A., Branco G., Fatigue behaviour of T welded joints rehabilitated by tungsten inert gas and plasma dressig, Materials and Design, vol 32, pp 47054713, 2011 